\title{
Improving the Socio-Economic Lot of Farmers in Thailand through Area-Yield Rice Crop Insurance at District Level
}

\author{
KRITTIYA DUANGMANEE \\ Faculty of Commerce and Management \\ Prince of Songkla University \\ Trang Campus, Muang District, Trang, 92000 \\ THAILAND
}

\begin{abstract}
Thai farmers face various risks associated with natural disasters, adversely affecting their income. Such events appear to be increasing each year in Thailand, which is one of the world leaders for harvested area of rice. Despite this, its yields are lower than various nations with a considerably smaller crop area. With a view to helping farmers to manage the relevant risks and so improve their socio-economic lot, there is a real need to adopt an agricultural financial tool called 'area-yield crop insurance'. Therefore, on the basis that area selection is the first key step towards introducing this type of policy at district level, this paper aims to group together similar districts. Hence the author conducted a cluster analysis of districts in six provinces in north-eastern Thailand. The results reveal differences between rice cultivation in the districts studied but also certain similarities, with the characteristics of some districts in a given province resembling those of districts in one or more other provinces. As a result, five groups of similar districts are mooted. These clusters, each having their own features, provide a powerful and useful mechanism for practical implementation, enabling the expected premium rates to be tailored better to the local context and mitigating a specific drawback, namely the basis risk of a prospective area-based crop insurance policy for the designated area.
\end{abstract}

Key-Words: area yield, cluster analysis, crop insurance, districts, rice, Thailand.

Received: August 22, 2020. Revised: December 31, 2020. Accepted: January 8, 2021. Published: January 15, 2021

\section{Introduction}

The Thai government's Eleventh National Economic and Social Development Plan 2012-2016 features, among other items, a "Strategy to Strengthen Food and Energy Security and the Agricultural Sector" [1]. This plan points out that the agricultural sector has been instrumental in shoring up the domestic food supply and enhancing the production base. The same key document also indicates that this is an industry which provides an income source for agricultural households, bolsters value creation for goods and services, and generates renewable energy. It proposes various means to achieve the objectives of, first, empowering the agricultural sector and, second, improving the job security, income, and quality of life of those working in this domain. One of the suggestions intended to meet these goals is crop insurance. Indeed, the number of farmers who use the crop-insurance system - which provides them with a considerable array of assistance - is an indicator of the success of this plan.

As is well known, rice forms part of Thais' staple diet. On top of this, Thailand ranks fifth in the world when it comes to harvested area of rice. However, it has lower yield levels than several countries with a substantially less sizeable crop area. This is due to several factors, including the occurrence of natural disasters. The number of these catastrophic events seems to have been rising each year, having a severe impact on Thai farmers. The present study adopts a promising risk-mitigation strategy involving rice crop insurance to safeguard their interests, namely the area-based approach, ultimately culminating in a rate-making process for financial intermediaries, e.g. insurance companies.

One study [2] posits that climate-related factors such as rainfall and rainy days have an influence on rice yields in six provinces in the north-eastern part of Thailand. That previous work only uses the provincial level to establish crop-insurance premium rates. Therefore, it is vital to investigate in depth the implementation of this type of policy at district level (which has not traditionally played a role in Thai insurance). This is because the first important step towards utilising area-yield index crop insurance is area selection, as it allows the anticipated premium rates to be better tailored to the relevant situations 
encountered there and the zone that is exposed to risks. Consequently, this paper aims to group the districts in question which are similar to each other using cluster analysis. The idea behind the clustering of observations is that members of the same group of observations should be alike, whereas observations from separate groups should be dissimilar. Grouping observations demands methods for calculating the distance between or the similarity/dissimilarity of every observation pair.

Moreover, [3] suggests that cluster analysis encompasses a panoply of methods for dividing multivariate data into subgroups, and that clustering - by categorising such data in these subgroups - can help to identify the features of any patterns or structure. As well as its pertinence in other areas, cluster sampling is especially useful in business when it is expensive or difficult to devise a full list of population members and when there are geographically widely dispersed population elements, as pointed out in [4].

Against this backdrop, this investigation's results could offer a useful and effective tool for the practical implementation of the relevant approach. In this way the anticipated premium rates can be adapted to fit the local context better, and also the drawback that is presented by the basis risk of a future area-based crop insurance policy for the respective area can be mitigated.

\section{Literature Review}

This section reviews the literature relating to, first, rice and crop-insurance management in Thailand and beyond and, second, area yield as a way of managing insurance for crops.

The initial focus, then, will be on the management of rice and crop insurance in Thailand and other countries.

Thailand features among the Asian countries where agriculture is the commonest land use. Rice is the country's leading harvested crop and its primary source of income, ahead of the other major typical Thai agricultural products. In fact, in 2011 Thailand ranked fifth in the world for harvested area of rice (11,630,300 hectares), as indicated in [5] - a position it replicated in 2017 (with a harvested area of rice of 10,614,829 hectares), according to [6].

However, in terms of harvested yield (29,740 hectograms per hectare), in 2011 it was outperformed by countries having a much smaller crop area, based on [5]. The 2017 data reveal that at that time, Thailand had a harvested yield of 31,125 hectograms per hectare, according to [6], i.e. it was still below countries with a smaller harvested area for rice, thus repeating the same pattern as six years previously.

The contrast between growing area and production is attributable to several factors, including natural catastrophes, since rice yield in many areas of Thailand predominantly depends on rainfall. On the other hand, one paper [7] reports that in Bangladesh, rice yield for ecotypes had a greater susceptibility to changes in temperature than rainfall effects. Furthermore, that study points to the need for suitable adaptation measures that are targeted to particular regions to reduce the variability of rice yield for the purpose of food security.

As regards agricultural risk, [8] suggests that agricultural risk can be roughly divided into two major categories, namely natural risk and market risk, and therefore management measures are split into production risk management and business risk management, respectively. Based on the same work, to disperse and transfer agricultural risks, market risk management tools, including insurance and future markets, were introduced. It is revealed in [9] that consistently, two typical root causes of farms' problems are (1) output fluctuations between one year and another as a result of technological developments, disease, and meteorological patterns, and (2) limited net farm revenues. In [10], it is indicated that for the most extreme risks, for example disaster risk, a combination of government funding and insurance is an appropriate tool in incomplete markets. This is also a corollary of the fact that the rationale characteristically given for government interventions in an economy's agricultural sector is the need to, for instance, ensure food security - a point made in [9]. Crucially, [11] mentions that one means of decreasing the economic impact of catastrophic events is provided by insurance or reinsurance. It presents two useful methods for estimating insured losses. It refers to these as the 'peaks over threshold' method and the 'block maxima' method.

In addition, another paper [12] asserts that insurance pricing and agricultural risk analysis through time and space are essential for the insurance market's sustainable development and agricultural producers' welfare. Therefore, that article proposes two interesting rate-making models for grain area-yield index insurance in China, namely a safety premium rate-making model based on spatially dependent risk adjustment and a pure premium rate-making model drawing on timevarying risk adjustment; and this could have implications in terms of the sustainability of catastrophe management. 
Thailand's original crop-insurance scheme was an indemnity insurance policy, set up in 1978, for all natural risks for cotton in Nakorn Ratchasrima Province's Pak Chong District (as set out in [13] and [14]). This programme was subsequently revived between 1982 and 1984. All-risks insurance was established for maize, sorghum, and soybean from 1990 until 1991. However, the programme was not a resounding success as indemnity payments outstripped collected premiums.

According to [15], in 2005 a Weather Index Insurance pilot scheme in Thailand was created by the World Bank, entailing technical assistance, consultancy activities relating to administrative formalities, monitoring of the pilot programme, and feedback on international experiences. In 2011, weather-index insurance for rice was launched, as reported in [13]. The programme seems to be faring even better than its predecessors, based on the increases that have been seen in the volume of insurance policies and the level of interest among farmers who would like to have this kind of insurance product (i.e. the average growth rates of the number of participants and insured farms seem to have risen). However, the sustainability of the programme still needs to be assessed.

All this also has its relevance for other countries. For example, [16], studying crop insurance in relation to farm production in India's Puducherry region, highlights various reasons why farmers refrain from purchasing insurance: (1) a lack of awareness owing to a lack of information; (2) a perception that buying such insurance would not be beneficial; and (3) less desirable features, such as (i) the scheme's area-based approach; (ii) delays in payments of claims; (iii) the level of indemnities; (iv) the complexity of the documentation; and (v) the delays caused by officials. Meanwhile, [17] presents the availability of index-based crop insurance in selected developing economies, including Philippines, Malawi, Thailand, Vietnam, and India, in 2017 and suggests that it is crucial to target eligible beneficiaries if heavy subsidised agricultural insurance is to be successful, in particular in developing countries.

As mentioned above, the main agricultural product in Thailand is rice. Generally speaking, if farmers experience unexpected losses from disasters which mean that they cannot begin growing crops immediately, some expenses which are not covered by the basic cropping costs will be compensated by the government (e.g. plant seed and plant nutrition). Thus, insurance is of interest both to save government finances and farmers' budgets, as it is used to subsidise losses, and to make sure that adequate support is provided to farmers when they are starting another crop cycle. Furthermore, while the government contributes to the insurance premium, this should cost it less than subsidising losses. Hence, the insurance company will cover the extra loss once the Disaster Relief Programme, under the government's supervision, has been compensated.

Additionally, a series of recommendations for executive action have arisen from the US Department of Agriculture (USDA) crop disaster programmes, namely (1) the development and maintenance of data system documentation; and (2) the development and implementation of a mechanism for linking internet-based payments to application data in Farm Service Agency (FSA) county offices' spreadsheets, with a view to establishing an integrated interim payment system (based on information in [18]). Crop insurance could be one of the tools that could be deployed for this purpose. According to [19], the responsibilities of insurance agents may encompass (1) adequately notifying farmers of applicable crop-insurance policy provisions; and (2) properly preparing and completing farmers' insurance applications, certification of their production history, acreage reports, and other sales-related documentation.

Attention now turns to the second aspect of this literature review, namely the use of the area-yield approach as a crop-insurance management tool, falling within the scope of quantitative finance.

Professor Harold G. Halcrow is generally regarded as the first scholar to have proposed the idea of area-yield crop insurance, with his defining 1949 paper [20] about this topic, as indicated by [21], [22], and [23]. Area-yield crop insurance involves indemnity payments and premiums on the basis of the area yield rather than the individual farm yield. Farmers or insured covered by an areayield crop insurance programme receive a claim payment if the actual area yield turns out to be below a given critical yield (also referred to as a guarantee or trigger yield) which is calculated based on the anticipated average area yield, a coverage level, and a scale level (as set out by [20], [23], and [24]).

In the early 1990s, [21] developed the ideas in Halcrow's article, and several related papers have been published in the years since then. An areayield crop insurance pilot in this type of insurance's infancy was the United States' Group Risk Plan (GRP). In [22], four main aspects are specified which need to be taken into consideration in designing an insurance policy: (1) the area selected; (2) the procedures used to predict the future area 
yield; (3) the payout rules; and (4) the reasonable ranges for the coverage and deductibles. As regards the first aspect, for selection of the area the principal idea is that the insured areas should be similar to each other in terms of for instance the precipitation, the temperature, and the crop type, i.e. the area's homogeneity, according to [25]. Therefore, in general, the regions selected are likely to be neighbours.

Area-yield crop insurance boasts a variety of striking benefits. One significant advantage is that it reduces adverse selection (which arises when farmers facing a high probability of losses seek insurance) and moral hazard (which entails farmers who hold insurance being more likely to engage in malpractice to increase the likelihood of loss), as pointed out by [24] and [26]. Moreover, as indicated above, the indemnities and premiums are mainly calculated based on the aggregate yield in the local area; consequently, crop insurance supplies coverage for all risks, such as flood and drought, and historical data from the individual farms are no longer needed, based on [25]. In [27], it is emphasised that systemic risk is not diversifiable, and so farmers in the region in question will be affected by the risk, and that area-yield insurance lessens the impact and can be easily transferred to reinsurers around the world. Moreover, that paper reveals that the financial burden of insurance is feasible, given that per hectare the premium paid by farmers (particularly those with small farms) in the same area is identical, along with the indemnity they receive.

Having said this, one drawback of area-yield crop insurance is that it is restricted to areas with basis risk. Appropriate selection of the area where area-yield crop insurance is to be implemented is the optimal solution for reducing the basis risk, along with the payout rules and the coverage and deductible ranges (as indicated by [22] and [27]). A paper [28] assessing gaps in the take-up of crop insurance makes clear that lowering basis risk is fundamental to (1) ensuring that providers and beneficiaries alike have confidence in such insurance, and to (2) widening the market that is available for index-based insurance. Tools used in their analysis include focused group discussions (FGD) carried out with rice farmers at village level in various districts.

To address this challenge, a group of similar districts will be examined with a view to managing an area-yield approach at district level. The key point is that the Thai insurance market does not yet offer area-based crop insurance, which is why examining this further is of particular interest.

\section{Method}

To investigate the management of area-based crop insurance at district level by exploring the characteristics of the selected districts and grouping together the similar districts in the provinces under scrutiny here, this study will be conducted on the basis of historical crop-rice data from districts in six provinces in north-eastern Thailand, i.e. (from west to east) Loei, Nongbualamphu, Nongkhai, Udonthani, Sakonnakhon, and Nakhonphanom. Additional sources of data include the Thai Office of Agricultural Economics' annual report.

The characteristics of the districts examined in the six provinces will be determined based on the factors presented in Table 1.

Table 1. Definition of variables

\begin{tabular}{|c|c|}
\hline Variable & Description \\
\hline Pop & The population of a given district \\
\hline Size & $\begin{array}{l}\text { The surface area of the district under } \\
\text { examination }\left(\mathrm{in} \mathrm{km}^{2}\right)\end{array}$ \\
\hline Farmers & $\begin{array}{l}\text { The number of farmers in the } \\
\text { respective district }\end{array}$ \\
\hline Yield & $\begin{array}{l}\text { Ratio of yield to harvested area } \\
\text { (kg/rai) }\end{array}$ \\
\hline Irrig & $\begin{array}{l}\text { Capacity of the relevant water bodies } \\
\left(\mathrm{Mm}^{3}\right)\end{array}$ \\
\hline RD6 & $\begin{array}{l}\text { Percentage of growing area where } \\
\text { RD6 major rice seed is cultivated } \\
\text { (percentage) }\end{array}$ \\
\hline Temp & $\begin{array}{l}\text { Minimum temperature in the course of } \\
\text { a year (degrees Celsius }\left({ }^{\circ} \mathrm{C}\right) \text { ) }\end{array}$ \\
\hline Rainfall & Level of rainfall per annum (ml) \\
\hline
\end{tabular}

Source: Author's own compilation

The variables defined above are vital for rice farmers. For instance, irrigation is a decisive factor because water bodies' capacity (i.e. their volume, and therefore indirectly their size) determines the amount of water supplied to rice paddies, and therefore if remote areas have no suitable irrigation systems, this will affect crops and production levels.

Cluster analysis, an approach described in [4] and [29], was applied to a group of homogeneous districts in this study. 'Clustering' is the term given to a wide range of techniques which are used to determine subgroups of observations that constitute a data set. The rationale behind the clustering of observations is that those observations that belong to the same group should be alike, while observations from distinct groups should be different. Grouping observations calls for methods 
that can calculate the similarity or dissimilarity of, or the distance between, every observation pair. The conventional methods for this purpose are Euclidean and Manhattan distances. Euclidean distance can be defined as follows ([3] and [29]):

$$
d(x, y)=\sqrt{\sum_{i=1}^{n}\left(x_{i}-y_{i}\right)^{2}}
$$

where $x$ and $y$ are vectors of length $n$.

Moreover, the k-means cluster approach and the hierarchical cluster approach differ in their identification of groups in the dataset, in that the former approach requires pre-specification of the number of clusters to be generated, whereas the latter does not, as indicated in [29].

This investigation deployed the commonest methods used for hierarchical cluster analysis, as per [30] - Euclidean distance (calculating the distance between or the similarity/dissimilarity of every observation pair) and complete linkage (entailing calculating all pairwise dissimilarities between the items in cluster 1 and those in cluster 2). This resulted in a cluster dendrogram and a heat map. Next, the appropriate number of clusters was worked out using additional methods, specifically a scree plot and a Bayesian Information Criterion (BIC) plot, as it has been demonstrated previously that this type of plot is highly effective in model-based clustering.

\section{Results}

This paper sets out to offer a fuller understanding of the characteristics of a Thai region by conducting an in-depth study of the district level, given that the first important step in introducing area-yield index crop insurance is area selection. Hence, the purpose is to group the districts in six similar provinces (listed here from west to east), Loei, Nongbualamphu, Nongkhai, Udonthani, Sakonnakhon, and Nakhonphanom, using cluster analysis.

Based on the features of the districts studied in these six provinces, individual groups of similar districts in the provinces under examination were identified. Initially, as different units are used for the variables collected, the data set was standardised. This investigation applied the commonest methods deployed for hierarchical cluster analysis, yielding a cluster dendrogram and a heat map. The cluster dendrogram suggests that while in most cases districts from the same province are similar, certain districts fall into the cluster of another province. In addition, the cluster dendrogram also gives a visual impression of the number of major significant clusters (between two and seven in this instance).

The districts were then presented in a heat map (Figure 1). Row dendrograms indicate the similarity (or distance) between rows and the nodes for each row, based on the clustering calculation, while column dendrograms show how similar the variables are. For instance, the variables 'Population' and 'Farmers' are more similar to each other than they are to the variable 'Yield'.

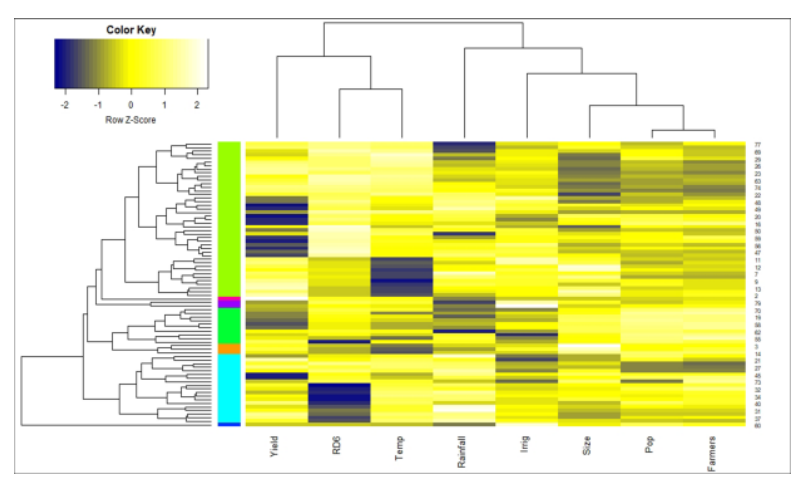

Fig. 1. Heat map

Source: Author's own compilation

Next, since the number of clusters was not determined in advance, the appropriate number of clusters was identified through other methods, specifically by means of a scree plot and with a Bayesian Information Criterion (BIC) plot. Based on the scree plot, if there are six clusters, this does not cause a major decrease in the value of the sum of squares within a group. Therefore, based on this method it would seemingly be reasonable to hypothesise five clusters. Furthermore, the BIC plot clearly supports this hypothesis. Based on this plot, the EEE model is the optimal model, identifying five clusters, with the lowest BIC value being -960.4468 .

Finally, five groups of similar districts based on the variables collected were established. Cluster 1 consists of 13 districts, whereas cluster 2 features 44 districts. Meanwhile, clusters 3, 4, and 5 comprise 19, 1, and 2 districts, respectively.

The characteristics of each cluster are set out in Table 2. Based on an average value for each cluster, a comparison is made with an average value for each variable investigated, with 'low' denoting 'lower than average', and 'high' signifying 'higher than average'. It appears that, for instance, cluster 2 
consists of a large number of districts, but the districts have a small population and a small surface area, a relatively low number of farmers, a low yield, a low level of capacity of the relevant water bodies, a low minimum temperature in the course of a year, and a low rainfall level per annum. However, in these districts the growing area where RD6 major rice seed is cultivated accounts for a substantial percentage of the total. The characteristics of the other clusters can be explained in a similar way.

Table 2. Characteristics of each cluster

\begin{tabular}{llllll}
\hline Variable & $\begin{array}{l}\text { Cluster 1 } \\
(13 \text { obs.) }\end{array}$ & $\begin{array}{l}\text { Cluster 2 } \\
(44 \text { obs. })\end{array}$ & $\begin{array}{l}\text { Cluster 3 } \\
(19 \text { obs. })\end{array}$ & $\begin{array}{l}\text { Cluster 4 } \\
\text { (1 obs.) }\end{array}$ & $\begin{array}{l}\text { Cluster 5 } \\
\text { (2 obs.) }\end{array}$ \\
\hline Pop & high & low & high & high & high \\
Size & high & low & low & high & high \\
Farmers & (v.) high & (v.) low & high & high & high \\
Yield & high & low & high & high & low \\
Irrig & low & low & low & (v.) high & (v.) high \\
RD6 & high & high & (v.) low & high & high \\
Temp & (v.) low & low & high & high & high \\
Rainfall & low & low & (v.) high & low & (v.) low \\
\hline Key: & & & & \\
Obs. =observation(s) & & & & \\
v. = very & & & &
\end{tabular}

Source: Author's own compilation

Figure 2 provides a visual representation of these results, showing clearly that some districts in each province are classified in the same group, or cluster.

There are two clusters in Loei: one consisting of only three districts (Muang District, Dan Sai, and Wang Saphung), and the other districts belonging to the other cluster.

Nongbualamphu numbers three clusters. Two of these are each made up of multiple districts, but Non Sang is completely different from the other districts in this province and so is the sole member of its cluster there.

All the districts in Nongkhai belong to a single cluster. This is unique for the provinces considered in this research.

In Udonthani, Mueang Udon Thani, on account of its status as the largest and most populous district studied here, belongs to its own cluster, not found in any of the other provinces investigated. Likewise, Kumphawapi and Wang Sam Mo are the only members of another cluster that was not encountered in any of the provinces examined. The province also has three other clusters (each of which are also encountered in other provinces), accounting for the rest of the districts in Udonthani.

Three clusters are represented in Sakonnakhon. Among the districts in this province, Akat Amnuai is similar to Ban Muang and so constitute one cluster; Mueang Sakon Nakhon, Phanna Nikhom, Sawang Daen Din, and Wanon Niwat make up another cluster; and the remaining cluster covers all the other districts.

In Nakhonphanom, there are three clusters: most of this province's districts fall into one cluster; the other two clusters are each made up of two districts: first, Mueang Nakhonphanom and $\mathrm{Na} \mathrm{Wa}$; and second, Pla Pak and Tha Uthen.

Please note that in the figure the one- or twoletter codes in brackets preceding the name of each district denote the respective province: '(L)' stands for 'Loei', '(NB)' for 'Nongbualamphu', '(NK)' for 'Nongkhai', '(U)' for 'Udonthani', '(S)' for 'Sakonnakhon', and '(NP)' for 'Nakhonphanom'.

The next part will present the relevant conclusions of this work.

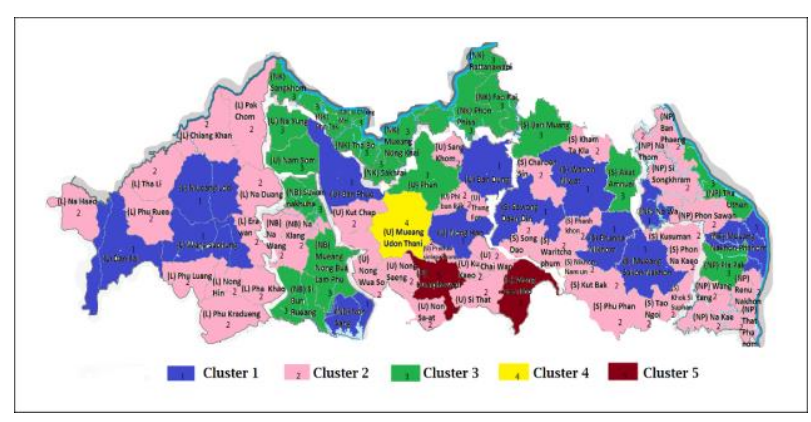

Fig. 2. Map showing district clusters

Source: Author's own compilation

\section{Conclusion}

A vital part has been played by the agricultural sector in consolidating the production base and ensuring Thailand's national food supply, while also offering a source of income for agricultural households, contributing to value creation in terms of goods and services, and producing renewable energy, based on the country's Eleventh National Economic and Social Development Plan 2012-2016. Rice is an essential component of Thais' staple diet. Furthermore, in international comparisons Thailand performs well for harvested area of rice but has lower yields than several nations with a substantially smaller crop area. A number of factors are responsible for this, among them the occurrence of natural disasters. The prevalence of such events appears to have been increasing every year, severely affecting Thai farmers. In this investigation, a promising approach, called the 'area-based approach', is adopted to mitigate risk for rice crop insurance, with a view to looking after these farmers' interests. Under this methodology, area selection is the first key step towards deriving the benefits of area-yield index crop insurance. In this light, the idea behind the present study was to perform an in-depth examination of the 
implementation of this insurance type at district level (which has not traditionally been a feature of insurance in Thailand). The purpose of this was to enable the expected premium rates to track the local situation more closely, with a view to grouping similar districts using cluster analysis.

This study was conducted in six provinces in north-eastern Thailand. On the basis of the variables investigated, it reveals that in a number of cases there are differences between districts in the same province. Additionally, among the provinces researched here, Mueang Udon Thani District (cluster 4) in Udonthani Province rather stands out from the other districts, having for example not only the largest population but also the biggest surface area. Thus, it is considered to fall into a cluster of its own. Moreover, cluster analysis, which can play a role in revealing the characteristics of any population of data, demonstrates its worth in this context. This technique suggests that there are five groups of similar districts, with individual districts in a province having characteristics similar to those of certain districts in another province or other provinces. In addition, each cluster has its own characteristics.

Some final remarks concerning the above results will now be presented. The first point to make here is that there are clearly differences between individual districts within a province. This means that a unique premium rate for all the districts in these six provinces would not be fit for purpose. The proposed clusters should be deployed in practice at the implementation stage, as this would enable the expected premium rates to be tailored more closely to the area exposed to risks and the relevant situations found there.

Besides, this approach could be expanded to other countries that have smallholders with limited knowledge of agricultural insurance and no farmlevel agricultural production data: a backdrop which means that area-yield index insurance at district (or county) level will be preferable to farm-yield crop insurance in these nations, as in Thailand.

Furthermore, area-yield crop insurance, as proposed by this study, is a solution geared to the situation on the ground, and so could make a valuable contribution to efforts to enhance the economic viability and sustainability of the rice industry. Specifically, this would arise in particular from the financial benefits that farmers would reap from more appropriate and targeted support from insurers applying the area-yield approach. Additionally, this approach could potentially be economically advantageous for other arms of the agricultural sector, such as the coffee, tea, and rubber industries, if rolled out there too.

Moreover, the present paper should be viewed in the broader context of insurance companies' significance as financial intermediaries and investment drivers. In this connection, agribusinesses in Thailand and elsewhere should consider leveraging Public-Private Partnerships (PPPs), reflecting those launched in various countries.

Last but certainly not least, the results will be used in the future to entrench the area-yield index approach. To this end, further steps will be taken towards drafting a suitable policy and extending the approach to more districts.

\section{References:}

[1] Office of the National Economic and Social Development Board (2012). The Eleventh National Economic and Social Development Plan 2012-2016. Retrieved from http://eng.nesdb.go.th/

[2] Duangmanee, K. (2015). Adaptation of Thai Insurance to Natural Disasters: An Analysis of Developments in Major Rice Crop Insurance Using the Area-Yield Approach (doctoral thesis). University of Antwerp, Antwerp, Belgium. Published only in printed format. Abstract retrieved from https://www.uantwerpen.be/popup/kalenderond erdeel.aspx ?calitem_id $=2578 \& c=L A N D P 289 \&$ $\mathrm{n}=222966$

[3] Everitt, B. S., Landau, S., Leese, M., \& Stahl, D. (2011). Cluster Analysis. Fifth edition. Chichester: Wiley.

[4] Keller, G. (2009). Managerial Statistics. Eighth edition. South-Western France: Cengage Learning.

[5] Food and Agriculture Organization of the United Nations (2011). Production. Retrieved from http://faostat.fao.org/site/339/default.aspx

[6] Food and Agriculture Organization of the United Nations (2017). Crops. Retrieved from http://www.fao.org/faostat/en/\#data

[7] Ara, I., Lewis, M., \& Ostendorf, B. (2017). Understanding the Spatially Variable Effects of Climate Change on Rice Yield for Three Ecotypes in Bangladesh, 1981-2010. Advances in Agriculture, 2017, 1-11. https://doi.org/10.1155/2017/6287156

[8] Jian, W., \& Rehman, A. (2018). Risk Management in Agriculture: Theories and Methods. New York: Science Publishing Group. 
[9] Penson, J. B., Jr, Capps, O., Jr, Rosson III, C. P., \& Woodward, R. T. (2015). Introduction to Agricultural Economics (global edition). Harlow: Pearson.

[10] Skees, J. R. (2008). Challenges for use of index-based weather insurance in lower income countries. Agricultural Finance Review, 68, 197-217. https://doi.org/10.1108/00214660880001226

[11] Jindrová, P., \& Pacáková, V. (2019). Natural Catastrophe Models for Insurance Risk Management. WSEAS Transactions on Business and Economics, 16, 9-17. Retrieved from

https://www.wseas.org/multimedia/journals/eco nomics/2019/a035107-699.php

[12] Li, X., Ren, J., Niu, B., \& Wu, H. (2020). Grain Area Yield Index Insurance Ratemaking Based on Time-Space Risk Adjustment in China. Sustainability, 2491. https://doi.org/10.3390/su12062491

[13] Jeerachaipaisarn, T. (2012). Recent Developments of Crop Insurance in Thailand. Presentation by Thanad Jeerachaipaisarn for the General Insurance Association, 26th January 2012, Bangkok, Thailand. Retrieved from http://www.oecd.org/insurance/insurance/4965 7525.pdf

[14] Lorchirachoonkul, V., \& Chaisilaparungruang, W. (2002). Crop Insurance Covering Production Cost. Bangkok: National Institute of Development Administration (NIDA). (In Thai)

[15] Manuamorn, O. (2009). Rainfall Index- Based Insurance for Maize Farmers in Thailand: Review of Pilot Program 2006-2008. Experiential briefing note prepared by Ornsaran Pomme Manuamorn, Agriculture and Rural Development Department, the World Bank, Washington D.C., United States, January 2009. Retrieved from http://documents1.worldbank.org/curated/fr/48 6101468312352024/pdf/775860BRI0Thai0Box 0342041B00PUBLIC0.pdf

[16] Jegadesan, S. (2016). Crop Insurance as a Risk Management Tool in Farm Production. Saarbrucken: Lap Lambert Academic Publishing.

[17] Reyes, C. M., Agbon, A. D., Mina, C. D., ～\& Gloria, R. A. B. (2017). Agricultural insurance program: Lessons from different country experiences. PIDS Discussion Paper Series, No. 2017-02, Philippine Institute for Development Studies (PIDS), Quezon City.
Retrieved

from http://hdl.handle.net/10419/173579

[18] United States Government Accountability Office (2011b). USDA Crop Disaster Programs: Lessons Learned Can Improve Implementation of New Crop Assistance Program. In A. M. Gil (Ed.), Agriculture Disaster and Crop Insurance (pp. 81-116). New York: Nova Science Publishers.

[19] United States Government Accountability Office (2011a). Crop Insurance: Opportunities Exist to Reduce the Costs of Administering the Program. In A. M. Gil (Ed.), Agriculture Disaster and Crop Insurance (pp. 117-144). New York: Nova Science Publishers.

[20] Halcrow, H. G. (1949). Actuarial structures for crop insurance. Journal of Farm Economics, 31, 418-443. https://doi.org/10.2307/1232330

[21] Miranda, M. J. (1991). Area-Yield Crop Insurance Reconsidered. American Journal of Agricultural Economics, 73, 233-242. https://doi.org/10.2307/1242708

[22] Skees, J. R., Black, J. R., \& Barnett, B. J. (1997). Designing and Rating an Area Yield Crop Insurance Contract. American Journal of Agricultural Economics, 79, 430-438. https://doi.org/10.2307/1244141

[23] Smith, V. H., \& Watts, M. (2009). Index Based Agricultural Insurance in Developing Countries: Feasibility, Scalability and Sustainability. Paper commissioned by the Bill and Melinda Gates Foundation under the Foundation's Global Development Program. Retrieved from https://citeseerx.ist.psu.edu/viewdoc/download? doi=10.1.1.476.4002\&rep=rep1\&type=pdf

[24] Awondo, S. N., Datta, G. S., Ramirez, O. A., \& Fonsah, E. G. (2012). Estimation of crop yield distribution and Insurance Premium using Shrinkage Estimator: A Hierarchical Bayes and Small Area Estimation Approach. 2012 Annual Meeting, Agricultural and Applied Economics Association, 12-14 August 2012, Seattle, Washington, D.C., United States. Retrieved from http://purl.umn.edu/126778

[25] Katie School of Insurance (2011). Establishing an Index Insurance Trigger for Crop Loss in Northern Ghana. Research Paper No. 7 of Illinois State University, United States. Retrieved from https://business.illinoisstate.edu/katie/download s/IndexInsuranceTriggersForCropLossInNorthe rnGhana.pdf

[26] Mahul, O. (1999). Optimal Area Yield Insurance. American Journal of Agricultural 
Economics, 81, 75-82. https://doi.org/10.2307/1244451

[27] Binici, T., \& Zulauf, C. R. (2006). Determining Wheat Crop Insurance Premium Based on Area Yield Insurance Scheme in Konya Province, Turkey. Journal of Applied Sciences, 6, 11481152.

http://dx.doi.org/10.3923/jas.2006.1148.1152

[28] Sinha, S., \& Tripathi, N. K. (2016). Assessing the Challenges in Successful Implementation and Adoption of Crop Insurance in Thailand. Sustainability, $\quad 8(12), \quad 1306$. https://doi.org/10.3390/su8121306

[29] Kassambara, A. (2017). Practical Guide to Cluster Analysis in R. New York: STHDA.

[30] Hair, J. F., Jr, Black, W. C., Babin, B. J., \& Anderson, R. E. (2014). Multivariate Data Analysis. Seventh edition. Harlow: Pearson.

\section{Acknowledgements}

The author would like to thank the editor and reviewers for their constructive feedback and wishes to express her particular gratitude to Professor Dr Martine Van Wouwe and Assistant Professor Dr Preecha Vichitthamaros. The research was funded (under contract MRG6080181) by the Thailand Research Fund (TRF) in cooperation with the Office of the Higher Education Commission (OHEC), which forms part of the Thai Ministry of Education.

\section{Creative Commons Attribution License 4.0 (Attribution 4.0 International, CC BY 4.0)}

This article is published under the terms of the Creative Commons Attribution License 4.0

https://creativecommons.org/licenses/by/4.0/deed.en_US 